\title{
Pelayanan Publik dengan Bus Rapid Transit (BRT) pada Sistem Transportasi Massa di Kota Pekanbaru
}

\author{
Tuti Khairani Harahap ${ }^{1}$, Syahrial Hasibuan ${ }^{2}$ \\ ${ }^{1}$ Fakultas Ilmu Sosial dan Ilmu Politik Universitas Riau. Pekanbaru. 28293. Indonesia \\ ${ }_{2}^{2}$ Fakultas Teknik Universitas Islam Indragiri. Tembilahan Hulu. 29200. Indonesia
}

\begin{tabular}{|c|c|}
\hline ARTICLE INFORMATION & A B S T R A C T \\
\hline $\begin{array}{l}\text { Received: August 31, } 2021 \\
\text { Revised: September 23, } 2021 \\
\text { Accepted: October 11, } 2021 \\
\text { Available online: October 31, } 2021\end{array}$ & \multirow{5}{*}{$\begin{array}{l}\text { Improving public services in the urban transportation system consists of improving } \\
\text { transportation facilities and infrastructure, improving inter-institutional relations and } \\
\text { increasing human resources. The transportation system for the city of Pekanbaru in } 2009 \\
\text { began to apply the concept of Mass Rapid Transit (MRT) under the name busway trans } \\
\text { metro Pekanbaru. Over time, the trans metro busway has shrunk to become a regular bus. } \\
\text { This can be seen that many MRT public facilities are not maintained and neglected so that } \\
\text { public confidence in the MRT continues to decline. Efforts to improve public services on a } \\
\text { sustainable mass transportation system in Pekanbaru City through a public service system } \\
\text { that is provided in the form of transportation facilities and infrastructure that exist on the } \\
\text { trans metro busway system in Pekanbaru City, as well as providing solutions in the form of } \\
\text { maximizing an ideal and suitable mass transportation system for the people of Pekanbaru } \\
\text { City. With the Bus Rapid Transit (BRT) model. }\end{array}$} \\
\hline KEYWORDS & \\
\hline Pekanbaru, Transportation, Busway & \\
\hline CORRESPONDENCE & \\
\hline $\begin{array}{l}\text { Name: Tuti Khairani Harahap } \\
\text { E-mail: rhieal.lenka@gmail.com }\end{array}$ & \\
\hline
\end{tabular}

\section{PENDAHULUAN}

Sistem transportasi terbaik bagi sebuah kota akan tergantung pada kondisi-kondisi dan pilihan-pilihan setempat serta akan melibatkan kombinasi dari beberapa teknologi. Jika arus penumpang sangat tinggi dan lahan untuk busway terbatas, opsi lainnya mungkin lebih baik, misalnya angkutan umum berbasis kereta, walaupun telah kita lihat bahwa BRT (Bus Rapid Transit) dapat mengakomodasi volume penumpang untuk menyesuaikan permintaan bahkan di kota-kota besar.

Oleh karenanya, penataan sistem transportasi umum harus dilakukan secara terpadu agar dapat mewujudkan pelayanan jasa transportasi yang seimbang dengan tingkat kebutuhan /permintaan yang layak dan dapat terjangkau oleh seluruh masyarakat. Penataan angkutan umum perkotaan ini dalam jangka panjang diharapkan dapat mengurangi ketergantungan masyarakat terhadap penggunaan kendaraan pribadi (Kurnianingtyas, et.al. 2020).

Suatu sistem angkutan umum yang baik di suatu wilayah perkotaan dapat meningkatkan mobilitas dalam wilayah perkotaan tersebut. Karena itu, diperlukan suatu sistem angkutan umum untuk suatu wilayah perkotaan, dengan mempertimbangkan aksesibilitas menuju lokasi pemberhentian, mobilitas sistem itu sendiri, serta integrasi dengan moda transportasi lain (Valentine, et.al, 2020).

Gunawan \& Kusnandar (2011) pola pemakaian lahan di kota besar kadang tidak mendukung pembangunan system transportasi umum berbasis kereta yang efisien, padahal system ini dipercaya sebagai solusi jangka panjang untuk mengatasi kemacetan di perkotaan. Selain faktor diatas, SDM pengelola juga harus di perhatikan. Penentuan sistem manajemen yang tepat, serta pemeliharaan dan perawatan merupakan faktor penting yang harus di perhatikan. Bus Rapid Transit (BRT) telah menunjukkan bahwa kualitas tinggi angkutan umum dapat memenuhi kebutuhan publik yang luas baik dalam hal biaya maupun tingkat kesulitannya. Banyak organisasi bersedia untuk membantu desa-desa di kota-kota berkembang untuk membuat transportasi umum yang efisien menjadi kenyataan. Dengan kepemimpinan politis, semuanya mungkin terjadi.

Secara umum tujuan pengoperasian BRT dibagi menjadi tiga aspek meliputi lingkungan, sosial, dan ekonomi. Ketiga aspek ini dijadikan dasar preferensi layanan. Akan tetapi, sangat disayangkan bila pengoperasian BRT ini tidak didukung penuh oleh masyarakat baik terutama pengguna. Keterlibatan pengguna sangat penting untuk menunjang keberlangsungan layanan transportasi (Romadlon \& Saintika. 2020).

Banyak kota telah mengembangkan variasi tema tentang pelayanan bus yang lebih baik serta konsep tempat tinggal dalam kumpulan karya terbaik daripada sebuah definisi yang tegas. Bus Rapid Transit adalah satu bentuk angkutan berorientasi pelanggan dan mengkombinasikan stasiun, kendaraan, perencanaan dan elemen-elemen sistem transportasi pintar ke dalam sebuah sistem yang terpadu dan memiliki satu identitas unik. Ciri-ciri Bus Rapid Transit termasuk koridor busway pada jalur terpisah-sejajar atau dipisahkan secara bertingkat dan teknologi bus yang dimodernisasi.

Peningkatan kualitas pelayanan transportasi perkotaan terutama transportasi massal seperti Buss Rapid Transit (BRT) menjadi hal penting dalam mengurangi kemacetan kota. Pembangunan transportasi berkelanjutan melalui 
pengembangan angkutan umum massal yang terpadu termasuk BRT adalah kunci utama dalam menjawab permasalahan transportasi di setiap kota di Indonesia (Riawan, 2018).

Bus Rapid Transit (BRT) atau busway merupakan bus dengan kualitas tinggi yang berbasis sistem transit yang cepat, nyaman, dan biaya murah untuk mobilitas perkotaan dengan menyediakan jalan untuk pejalan kaki, infrastruktur, operasi pelayanan yang cepat dan sering, perbedaan keunggulan pemasaran dan layanan kepada pelanggan. Bus Rapid Transit (BRT), pada dasarnya mengemulasi karakteristik kinerja sistem transportasi kereta api modern (Nurfadli, et.al. 2015). Bus Rapid Transit merupakan lebih dari sekadar operasional sederhana di atas jalur eksklusif bus atau busway. Sementara, sistem Bus Rapid Transit selalu mencakup beberapa bentuk jalur khusus eksklusif untuk bus-bus, sebagian besar adalah busway yang sejajar dengan lapisan jalan.

Pengertian pelayanan menurut Barata (2003:27) yang mengemukakan bahwa pelayanan adalah kepedulian kepada pelanggan dengan memberikan layanan terbaik untuk memfasilitasi kemudahan pemenuhan kebutuhan dan mewujudkan kepuasannya agar mereka selalu loyal kepada organisasi.

Menurut Faozan (2003:125) bahwa pelayanan yang berkualitas dapat dilihat dari bukti langsung, kehandalan dalam memberikan pelayanan, kepekaan atau daya tanggap, jaminan dan kemampuan untuk memahami kebutuhan palanggan.

Sedangkan Bambang (2001:19) memandang Pelayanan Publik lebih kepada kemampuan organisasi untuk mengenali kebutuhan masyarakat, menyusun agenda dan prioritas pelayanan dan mengembangkan program - program pelayanan publik sesuai dengan kebutuhan dan aspirasi masyarakat. Untuk mendapatkan pelayanan yang berkualitas ada beberapa kriteria yang menurut Bambang (2003;27) perlu diperhatikan, yaitu:

- Tepat dan relevan, artinya pelayanan harus mampu memenuhi preferensi, harapan dan kebutuhan individu dan masyarakat;

- Tersedia dan terjangkau, artinya pelayanan harus dapat dijangkau oleh setiap orang atau kelompok yang mendapatkan prioritas;

- Dapat menjamin rasa keadilan, artinya terbuka dalam memberi perlakuan terhadap individu atau sekelompok orang dalam keadaan yang sama;

- Dapat diterima, artinya pelayanan memiliki kualitas apabila dilihat dari teknis/cara, kualitas, kemudahan, kenyamanan, menyenangkan, dapat diandalkan, cepat, tepat waktu, responsif dan manusiawi;

- Ekonomis dan efisien, artinya dari sudut pandang pengguna pelayanan dapat dijangkau melalui tarif dan pajak oleh semua lapisan masyarakat.

- Efektif, artinya menguntungkan bagi pengguna dan semua lapisan masyarakat.

Dalam kegiatan operasional pemerintahan konsep pelayanan publik diterjemahkan ke dalam Keputusan Menteri Penertiban Aparatur Negara (KepMenPAN) Nomor 63/KEP/M.PAN/7/2003 yang berbunyi: Segala kegiatan pelayanan yang dilaksanakan oleh penyelenggara pelayanan publik (negara) sebagai upaya pemenuhan penerima pelayanan maupun pelaksana ketentuan peraturan perundang-undangan. Kegiatan pelayanan publik berpedoman atas 10 (sepuluh) prinsip:

1. Kesederhanaan, Prosedur pelayanan publik tidak berbelit- belit, mudah dipahami, dan mudah dilaksanakan.

2. Kejelasan,

a. Persyaratan teknis dan administratif pelayanan publik;

b. Unit kerja / pejabat yang berwenang dan bertanggung jawab dalam memberikan pelayanan dan penyelesaian keluhan/ persoalan/ sengketa dalam pelaksanaan pelayanan publik.

c. Rincian biaya pelayanan publik dan tatacara pembayaran.

3. Kepastian Waktu, Pelaksanaan pelayanan publik dapat diselesaikan dalam kurun waktu yang telah ditentukan.

4. Akurasi, Produk pelayanan publik diterima dengan benar, tepat, dan sah.

5. Keamanan, Proses dan produk pelayanan publik memberikan rasa aman dan kepastian hukum.

6. Tanggung jawab, Pimpinan penyelenggara pelayanan publik atau pejabat yang ditunjuk bertanggung jawab atas penyelenggaraan pelayanan dan penyelesaian keluhan/ persoalan dalam pelaksanaan pelayanan publik.

7. Kelengkapan Sarana dan Prasarana, Tersedianya sarana dan prasarana kerja, peralatan kerja dan pendukung lainnya yang memadai termasuk penyediaan sarana teknologi telekomunikasi dan informatika (telematika).

8. Tempat dan lokasi serta sarana pelayanan yang memadai, mudah dijangkau oleh masyarakat, dan dapat memanfaatkan teknologi telekomunikasi dan informatika.

9. Kedisiplinan, Kesopanan dan Keramahan Pemberi pelayanan harus bersikap disiplin, sopan dan santun, ramah, serta memberikan pelayanan dengan ikhlas.

10. Kenyamanan, Lingkungan pelayanan harus tertib, teratur, disediakan ruang tunggu yang nyaman, bersih, rapi, lingkungan yang indah dan sehat serta dilengkapi dengan fasilitas pendukung pelayanan.

kinerja pelayanan transportasi kota yang termasuk dalam kategori baik adalah load factor pada jam sibuk, load factor di luar jam sibuk, kecepatan perjalanan, waktu perjalanan, jumlah kendaraan beroperasi, waktu tunggu. Kriteria kinerja transportasi yang termasuk dalam kategori sedang waktu pelayanan, awal dan akhir perjalanan. Sedangkan dalam kategori kurang yaitu headway dan frekuensi. (Dwiryanti \& Ratnasari, 2013).

Sejak tahun 2009, Kota Pekanbaru mulai di lakukan uji coba pembenahan sistem transportasi massa yang ideal, maka busway adalah jawabannya. Sistem transportasi ini berjalan dengan lancar dan mendapatkan antusiasme positif dari masyarakat. Sarana dan prasarana yang diberikan pemerintah berupa jalur khusus untuk busway, halte tertutup lengkap dengan pelayanan karcisnya serta pelayanan jalur dari pusat kota hingga pinggiran kota. Berdasarkan Keputusan Menteri Perhubungan Nomor KP.1ll Tahun 2009 Tentang Kota Pekanbaru termasuk kota percontohan di bidang transportasi.

Namun pada tahun 2017, alat transportasi massa ini mengalami penyusutan yang sangat signifikan. Semula kapasitas bus yang dapat menampung hingga 100 penumpang 
lebih berubah menjadi bus dengan kapasitas \pm 60 penumpang, penghilangan jalur khusus bus, serta penyediaan halte yang hanya sealakadarnya tanpa pelayanan karcis. Kondisi ini sangat memperihatinkan yang seharusnya pelayanan untuk transportasi massa menjadi maksimal, sekarang menyusut tanpa ada pelayanan sama sekali alias menjadi seperti sarana bus kota biasa. Padahal aspek operasional sebagai aspek yang terkait langsung dengan penyediaan pelayanan terhadap masyarakat tentunya masyarakat akan menuntut sistem BRT ini untuk memberikan kualitas pelayanan yang lebih baik jika dibandingkan dengan sistem pelayanan angkutan umum eksisting (Vidhia \& Hendra. 2021).

Beberapa penelitian menyatakan bahwa sistem BRT yang dirancang dan dioperasikan dengan tepat menawarkan pendekatan inovatif untuk menyediakan layanan transportasi berkualitas tinggi. Kondisi ini, sebanding dengan layanan kereta api tetapi dengan biaya yang relatif rendah dan waktu implementasi yang singkat. Peran teknologi Intelligent Transportation Systems juga turut mempengaruhi efisiensi operasional, kinerja teknis dan masalah biaya yang terkait dengan BRT (Dita \&Wirawan, 2020).

Sitorus \& Nur Uddin (2020) Dalam sistem moda Bus Rapid Transit (BRT), ketepatan dalam menentukan lokasi dan jumlah halte merupakan dua aspek yang penting dalam keberhasilan layanan angkutan umumnya.

Upaya meningkatkan pelayanan publik pada sistem transportasi massa berkelanjutan di Kota Pekanbaru menelaah sistem pelayanan publik yang diberikan serta kondisi fasilitas publik berupa sarana dan prasarana transportasi yang ada pada sistem busway di Kota Pekanbaru, serta memberikan solusi berupa memaksimalkan sistem transportasi massa yang ideal dan cocok bagi masyarakat Kota Pekanbaru dengan model Bus Rapid Transit (BRT).

\section{METODE}

Metode penelitian dalam penulisan ini menggunakan metode kualitatif evaluatif. Data kualitatif diperoleh dengan melakukan survey primer di lapangan dan menampilkan data berupa photo dan wawancara dengan masyarakat pengguna alat transportasi di kota Pekanbaru. Pujastaawa (2016) Teknik wawancara merupakan cara sistematis untuk memperoleh informasi-informasi dalam bentuk pernyataan-pernyataan lisan mengenai suatu obyek atau peristiwa pada masa lalu, kini, dan akan datang. Jenis wawancara yang digunakan adalah wawancara terencana, dengan menentukan responden atau informan terhadap pihak yang memiliki pengetahuan dan pengalaman terkait pelayanan BRT di Kota Pekanbaru, yang menurut Pujastaawa (2016) bahwa wawancara terencana dilakukan untuk memperoleh bahan-bahan informasi sesuai dengan tema yang telah direncanakan yang sebelumnya pewawancara terlebih dahulu harus menyiapkan interview guide (pedoman wawancara) dan menentukan narasumber atau informan yang relevan. Untuk memperoleh data yang akurat, wawancara di lakukan dengan menentukan informan berdasarkan pengguna BRT sesuai jalur trayek, yang masingmasing jalur trayek mewakili satu informan yang jumlah informan keseluruhan adalah 8 informan.

Survey data sekunder dilakukan dengan studi literature terhadap penelitian terdahulu dan data yang diperoleh dari Pemerintah Daerah Kota Pekanbaru yang terkait dengan urusan masalah transportasi kota.
Analisis data mengacu kepada konsep pelayanan publik dalam Keputusan Menteri Penertiban Aparatur Negara (KepMenPAN) Nomor 63/KEP/M.PAN/7/2003 yang berpedoman pada 10 (sepuluh) prinsip, yaitu: kesederhanaan, kejelasan, kepastian waktu, akurasi, keamanan, tanggung jawab, kelengkapan sarana dan prasarana, tempat dan lokasi, kedisiplinan dan kenyamanan.

\section{HASIL DAN PEMBAHASAN}

Perencanaan dan penerapan sistem transportasi kota yang ideal harus bersinergi atau berkesinambungan dengan sistem pelayanan yang diterapkan, terutama dalam meningkatkan aspek Sumber Daya Manusia (SDM) yang ada di dalamnya. Manajemen SDM ini yang apabila di kelola dengan baik dan profesional dapat menciptakan pelayanan transportasi kota yang baik pula sehingga mampu mengurangi tingkat kecelakaan yang tinggi, serta menciptakan keamanan dan kenyamanan dalam berkendaraan. Peningkatan pelayanan publik dalam sistem transportasi kota terdiri dari peningkatan sarana dan prasarana transportasi, peningkatan hubungan antar kelembagaan dan peningkatan SDM yang terlibat di dalamnya.

SDM yang terlibat dalam pelayanan sistem transportasi kota terdiri dari para pemangku kebijakan, karyawan dan pekerja-pekerja yang ada di dalam instansi yang bertanggung jawab atas pelayanan sistem transportasi kota ini. Sedangkan instansi yang terlibat dalam sistem transportasi massa di Kota Pekanbaru terdiri dari Dinas Perhubungan Kota, Kepolisian dan Pemerintah Kota.

Peningkatan sarana dan prasarana transportasi salah satunya melalui penyediaan sarana halte/shelter yang lengkap dan memadai serta terjamin keamanan dan kenyamanannya. Secara teknis, bentuk fasilitas shelter/halte yang berbeda-beda tanpa mempertimbangkan aspek keamanan dan keselamatan dapat mengarah pada potensi bahaya sehingga dapat memungkinkan terjadinya kecelakaan. Kondisi tersebut dapat dilihat dari beberapa sarana yang tersedia di beberapa sarana halte seperti tempat duduk, anjungan dan tangga naik penumpang. Ketidaktersediaan sandaran punggung di tempat duduk dan pegangan tangan yang berfungsi menjaga keseimbangan tubuh dapat mengakibatkan pengguna layanan terjatuh sehingga mengakibatkan cidera pada beberapa bagian tubuh (Nugroho, 2021).

Institute for Transportation and Development Policy (ITDP, 2002) menyebutkan bahwa Pengalaman dari beberapa kotakota berkembang menunjukkan bahwa pola kebijakan yang mendukung bagi MRT (Mass Rapid Transit) ini akan lebih mudah dicapai dimana satu badan institusional menyediakan perencanaan dan peraturan MRT. Dengan kata lain diperlukan adanya badan khusus/independen untuk mengelola dan mengoperasikan sistem transportasi massal dalam suatu kota yang tujuannya untuk mengendalikan kemacetan dan mempermudah perjalanan asal dan tujuan massa.

\section{Pelayanan Publik pada BRT trans metro Kota Pekanbaru}

Kesederhanaan. Pada tahun 2009 Pemerintah Kota Pekanbaru telah melakukan pembenahan di bidang transportasi massa dengan menghadirkan busway trans metro sebagai solusi untuk menghindari terjadinya kemacetan di ibukota. Prosedur pelayanannya juga jelas dan tidak berbelitbelit dan mudah untuk dilaksanakan dengan ditandai 
tersedianya infrastruktur pelayanan yaitu: tersedianya jalur khusus busway, tersedianya fasilitas halte tertutup lengkap dengan pelayanan karcis, kemudahan pelayanan karcis terusan bagi penumpang yang ingin pindah jalur, tersedianya terminal yang memadai (Terminal BRPS) dan fasilitas bus yang besar dan nyaman.

Kejelasan. Dalam pelaksanaannya pelayanan busway trans metro sudah sangat memadai. Pada setiap halte bus sudah dilengkapi dengan petunjuk prosedur teknis bagi penumpang busway dan juga terdapat gambar jalur-jalur busway, sehingga setiap penumpang dapat memilih bus sesuai arah tujuannya yang ditandai dengan nomor bus. Untuk manajemen pengelolaan busway trans metro ditangani langsung oleh unit kerja Dinas Perhubungan Kota Pekanbaru. Keberadaan busway trans metro ini pada tahun 2009 lalu dapat menyerap banyak tenaga kerja dimulai dari penerimaan supir bus (driver), pemeriksa karcis bus, petugas penjualan karcis dan para pegawai untuk unit manajemen transportasi kota di Dinas Perhubungan Kota Pekanbaru.

Kepastian waktu. Setiap bus memiliki jadwal ketepatan waktu untuk tiba dan waktu menaikkan/menurunkan penumpang di setiap halte busway trans metro. Untuk itu setiap calon penumpang dapat menunggu bus yang datang setiap 30 menit dan bus hanya menerima penumpang di halte yang sudah disediakan, dan bus tidak menunggu penumpang. Jumlah penumpang busway trans metro pada tahun $2017 \mathrm{~s} / \mathrm{d}$ tahun 2020 pada Tabel 1.

Tabel 1. Jumlah Penumpang Busway Trans Metro Kota Pekanbaru

\begin{tabular}{ccr}
\hline \multirow{2}{*}{ No } & Tahun & \multicolumn{2}{c}{ Jumlah (Orang) } \\
\cline { 3 - 3 } & \multicolumn{2}{c}{ Naik/Turun } \\
\hline 1 & 2020 & 3.512 \\
2 & 2019 & 3.225 .716 \\
3 & 2018 & 3.602 .653 \\
4 & 2017 & 3.581 .062 \\
\hline Sumber: Profil Dinas Perhubungan Kota Pekanbaru, 20021
\end{tabular}

Menurunnya jumlah penumpang yang naik/turun yang signifikan pada BRT Trans Metro Pekanbaru pada tahun 2020 dikarenakan tidak adanya pelayanan operasional yang disebabkan oleh pandemic Covid-19. Trans Metro Pekanbaru mulai operasi kembali pada awal tahun 2021 setelah Kota Pekanbaru menjadi zona hijau Covid-19.

Akurasi. Pelaksanaan program SAUM (Sarana Angkutan Umum Massa) melalui busway trans metro mendapat sambutan dan antusiasme masyarakat Kota Pekanbaru. Hal ini ditandai dengan tingginya keinginan dan rasa ingin tahu masyarakat mengenai busway trans metro.

Keamanan. Setiap fasilitas-fasilitas busway trans metro mulai dari terminal, halte hingga bus itu sendiri ditempatkan satu orang petugas keamanan guna untuk memberikan pelayanan maksimum kepada masyarakat dan mendorong masyarakat untuk naik bus.

Tanggung Jawab. Pimpinan penyelenggara busway trans metro memiliki tanggung jawab penuh terhadap pelayanan busway trans metro. Di setiap bus di fasilitasi tempat angket kosong untuk para penumpang yang tujuannya agar setiap keluhan dan masukan dari penumpang dapat dituliskan di angket ini dan ditempatkan kembali ke tempatnya supaya dapat dikumpulkan oleh kenek bus untuk di berikan kepada manajemen setiap harinya. Pada saat itu Busway Trans Metro masih di kelola oleh BUMD Kota Pekanbaru.

Kelengkapan sarana dan prasarana. Pada saat peresmian busway trans metro Kota Pekanbaru, pemerintah daerah telah melengkapi seluruh sarana dan prasarana busway trans metro yang baik dan memadai. Untuk halte disediakan fasilitas yang sangat memadai dilengkapi dengan halte tertutup, di sediakan electronic display trayek/jalur, pelayanan karcis, pelayanan keamanan (security), bahkan disediakan pula display untuk iklan komersil.

Tempat dan lokasi. Tempat dan lokasi pelayanan busway trans metro sangat memadai dan mudah dijangkau masyarakat. Untuk jalur-jalur yang tidak dilalui busway trans metro disediakan bus pengumpan (feeder) dan angkutan kota lainnya (oplet). Lokasi Koridor dan trayek Trans Metro Pekanbaru saat ini pada Tabel 2.

Tabel 2. Koridor Trans Metro Pekanbaru, Tahun 2020

\begin{tabular}{|c|c|c|c|}
\hline \multirow{2}{*}{ No } & \multirow{2}{*}{ Koridor/Trayek } & \multicolumn{2}{|c|}{ Jumlah Armada (Unit) } \\
\hline & & Beroperasi & Kebutuhan \\
\hline 1 & Koridor I Pandau-Pelita Pantai & 13 & 18 \\
\hline 2 & $\begin{array}{l}\text { Koridor II Terminal BPRS- } \\
\text { Kulim PP }\end{array}$ & 26 & 22 \\
\hline 3 & Koridor III Kampus UIN-MTQ & 16 & 22 \\
\hline 4 & Koridor IV Pasar Pusat-Kulim & 5 & 6 \\
\hline 5 & $\begin{array}{l}\text { Koridor V Pasar Lima Puluh - } \\
\text { Simpang Panam }\end{array}$ & & \\
\hline 6 & $\begin{array}{l}\text { Koridor IV Terminal BPRS- } \\
\text { Torganda }\end{array}$ & 5 & 5 \\
\hline 7 & $\begin{array}{l}\text { Koridor VII Tangkerang Dalam } \\
\text { - Terminal AKAP }\end{array}$ & & \\
\hline 8 & $\begin{array}{lll}\text { Koridor VIII } & \text { Kubang } & - \\
\text { Terminal AKAP } & & \end{array}$ & - & - \\
\hline
\end{tabular}

Kedisiplinan. Kesopanan dan Keramahan Pemberi pelayanan harus bersikap disiplin, sopan dan santun, ramah, serta memberikan pelayanan dengan ikhlas. Setiap petugas pelayanan busway trans metro sudah dibekali pendidikan dan pelatihan sebelum bekerja di busway trans metro.

Kenyamanan. Setiap fasilitas ruang tunggu khusus busway trans metro baik di terminal maupun di setiap halte telah disediakan fasilitas ruang tunggu yang nyaman, bersih, rapi, lingkungan yang indah dan sehat serta dilengkapi dengan fasilitas pendukung pelayanan dan lansekap (taman bunga).

Namun pada tahun 2017 transportasi massa busway trans metro telah berubah menjadi Bus Rapid Transit (BRT) dengan mengurangi kapasitas penumpang bus, yang semula bus mampu menampung kapasitas penumpang hingga 100 orang menjadi bus kecil yang hanya menampung \pm 50-60 penumpang. Sejak tahun 2020 Bus Rapid Transit (BRT) mengalami penyusutan lagi menjadi bus biasa hal ini dapat dilihat dengan menghilangnya jalur busway dari jalan raya.

Sarana dan prasarana bus juga mengalami penyusutan yang semula memiiki halte pemberhentian lengkap dengan petugas karcis (Gambar 1) dan sekarang hanya menyediakan tangga pemberhentian bus tanpa adanya perlindungan penumpang terhadap cuaca (panas matahari dan hujan pada Gambar 2). Sarana halte bekas peninggalan busway trans metro saat ini masih beroperasi sebagai halte penumpang namun 
keberadaan petugas karcis sudah tidak ada lagi, bahkan sarana ini seringkali menjadi tempat mangkalnya para pegagang, pengamen jalanan dan pengemis ibu kota sehingga tingkat keamanan penumpang di dalam halte sudah tidak kondusif. Padahal menurut Fakhtian \& Budiharjo (2021) Halte adalah lokasi dimana penumpang dapat naik ke dan turun dari angkutan umum dan lokasi di mana angkutan umum dapat berhenti untuk menaikan dan menurunkan penumpang, sesuai dengan pengaturan operasional sebagai kebutuhan dasar untuk layanan bus umum, desain lokasi halte harus memenuhi

Parameter tertentu seperti jarak dari titik asal/tujuan ke halte dan waktu berjalan, kondisi fisik halte harus ergonomis dan tahan cuaca. Berikut disajikan pada gambar 1 dan 2 tentang fasilitas halte bus di Kota Pekanbaru dan di Pinggiran Kota Pekanbaru

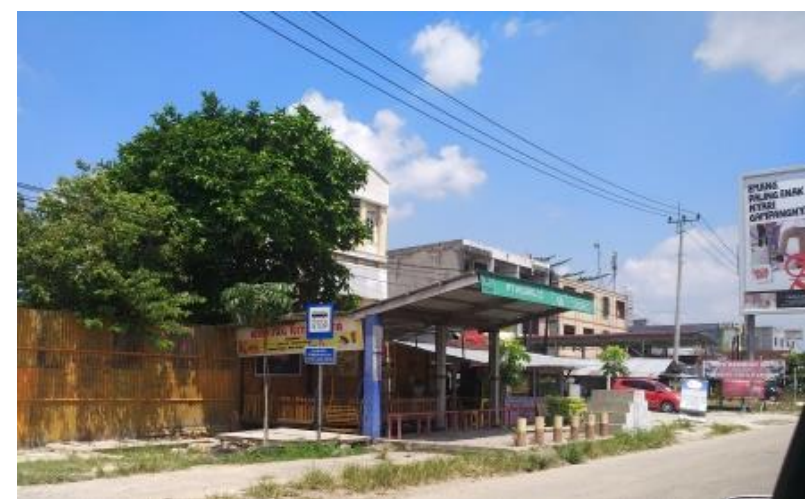

Gambar 1. Fasilitas Halte Bus Kota Pekanbaru (2021).

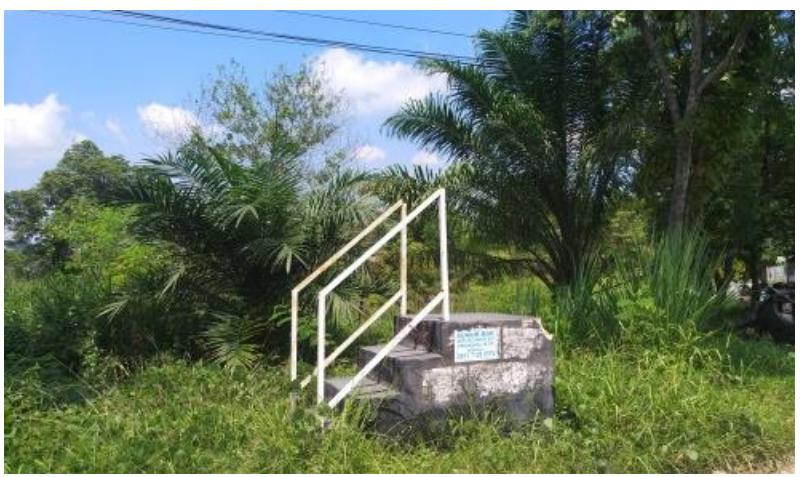

Gambar 2. Fasilitas Halte Bus di Pinggiran Kota Pekanbaru (2021).

Berdasarkan hasil survey dan wawancara terhadap masyarakat di lingkungan Dinas Perhubungan Kota Pekanbaru bahwa menyusutnya dan menghilangnya busway trans metro di Kota Pekanbaru dikarenakan cost revenue nya tidak berbanding lurus dengan biaya perawatan dan peningkatan fasilitas. Atau dengan kata lain adalah rugi. Dan tahun 2016 Pemerintah Kota Pekanbaru telah menjual unit busway kepada Pemerintah Daerah Kota Bandar Lampung dan menggantinya dengan bus rapid transit (BRT). Namun pada akhir tahun 2019 sistem pelayanan transportasi BRT ini berubah menjadi seperti bus biasa. Karena konsep pelayanan publik pada pedoman 10 (sepuluh) prinsip yang dicanangkan (KepMenPAN) Nomor 63/KEP/M.PAN/7/2003 sudah tidak berjalan lagi.

Beralihnya pengelolaan bus Trans Metro Pekanbaru dari Badan Usaha Milik Daerah (BUMD) Kota Pekanbaru PT
Sarana Pembangunan Pekanbaru (SPP) ke Dinas Perhubungan (Dishub) Kota Pekanbaru berdampak pada pelayanan. Hal ini dikarenakan peralihan pelayanan tidak disertai pelimpahan dengan jumlah armada. Sebelum ketika dikelola PT SPP, jumlah armada ada 50 unit. Sedangkan saat dikelola oleh Dishub, sejak per 1 Januari 2017, jumlah armada cuma 30 unit. Akibatnya kini operasional pun kini hanya pada lima koridor.

30 bus itu hanya bisa melayani masyarakat di lima koridor. Sementara jumlah koridor yang ada 10. Adapun kelima koridor yang terlayani itu, yakni koridor 1 Pandau-Pelita Pantai, koridor 2 Terminal BRPS - Kulim PP, Koridor 3 Kampus UIN - MTQ, Koridor 4A Pasar Pusat - Kulim dan Koridor 6 Terminal BRPS-Torganda. Kondisi ini menyebabkan mobilitas masyarakat yang sehari-hari bergantung pada TMP terganggu. Di beberapa halte, waktu tunggu yang biasanya sekitar 10 menit mengalami penundaan hingga lebih dari 30 menit.

Hasil wawancara dengan Plt Walikota Pekanbaru yang dikutip dari Jawa Post.com bahwa:

"Titik terang perbaikan pelayanan sendiri sudah mulai nampak pekan ini. Dishub sudah mendapat izin untuk mengoperasikan 15 unit armada tambahan. Seleksi langsung dilakukan untuk personel pramudi dan pramugara/i sebayak 68 orang. Awal Februari 2021 diperkirakan 45 bus sudah beroperasi. Di tahun 2017, Pemko Pekabaru menyiapkan anggaran operasional untuk 45 unit TMP sebesar Rp 23 miliar. Proses penambahan ini harus dilakukan dengan cepat. Perubahan yang terjadi seperti kewenangan penuh untuk mengelola TMP yang kini berada di Dishub perlu diperhitungkan dengan cermat. "Ini yang kita minta percepatan dari SKPD untuk mengantisipasi itu semua,"

Namun apa yang disampaikan oleh Plt Walikota Pekanbaru tersebut hingga saat ini tahun 2021 system pelayanan TMP belum juga terlaksana maksimal. Mungkin hal ini disebabkan terkendalanya pengelolaan karena adanya wabah Covid-19, sehingga penggunaan anggaran lebih difokuskan ke penanggulangan wabah Covid-19. Perbaikan dan peningkatan sarana dan prasarana transportasi TMP ini diharapkan dapat menghidupkan kembali kegiatan perekonomian masyarakat pasca Covid-19, yang menurut (Sulistyorini, 2021) Prasarana dan sarana transportasi mempunyai peran yang sangat penting dalam mendorong pertumbuhan wilayah sekaligus sebagai pendorong tumbuhnya perekonomian masyarakat dengan tersedianya sarana dan prasarana, seperti jalan, terminal, pelabuhan laut, dan bandar udara.

Upaya peningkatan transportasi massa di Kota Pekanbaru harus dilakukan dengan mengembalikan sistem transportasi angkutan umum biasa menjadi sistem transportasi massa dengan konsep Bus Rapid Transit (BRT). Model bus rapid transit (BRT) sangat cocok untuk diterapkan kembali, hal ini dikarenakan biaya investasi dan perawatan BRT tidak sebesar Busway Trans Metro. Peningkatan kembali sarana umum ini dilakukan supaya timbulnya kembali kesadaran masyarakat Kota Pekanbaru untuk menggunakan fasilitas BRT, dimana saat ini sejak tahun 2018 masyarakat cenderung lebih menyukai menggunakan kendaraan pribadi daripada transportasi massa.

\section{KESIMPULAN}

Pada tahun 2017 transportasi massa busway trans metro telah berubah menjadi Bus Rapid Transit (BRT) dengan mengurangi kapasitas penumpang bus. Namun pada akhir tahun 2019 
sistem pelayanan transportasi BRT (bus rapid transit) ini berubah menjadi seperti bus biasa. Hal ini dikarenakan biaya investasi dan perawatan fasilitas sangat tinggi dan terjadinya peralihan pengelolaan, yang semula di kelola oleh BUMD PT SPP (Sarana Pembangunan Pekanbaru), jumlah armada ada 50 unit. Sedangkan saat dikelola oleh Dishub, sejak per 1 Januari 2017, jumlah armada cuma 30 unit.

Upaya peningkatan transportasi massa di Kota Pekanbaru harus dilakukan dengan mengembalikan sistem transportasi angkutan umum biasa menjadi sistem transportasi massa dengan konsep Bus Rapid Transit (BRT), dimana harus ada komitmen yang jelas dari Pemerintah Daerah Kota Pekanbaru untuk mewujudkannya kembali. Sebab apabila terus dibiarkan maka untuk ke depannya Kota Pekanbaru akan menjadi kota dengan tingkat kemacetan lalu lintas yang tinggi dan kota yang penuh dengan polusi udara.

\section{REFERENSI}

Barata, Adya, Atep. 2003. Dasar-Dasar Pelayanan Prima. Penerbit PT Elex Media Komputindo Gramedia. Jakarta

Faozan. 2003. Peranan Birokrasi, Manajemen Kebijakan dan Eksistensi Pelayanan Publik (Teropong Fenomena dan Tawaran Jalan Alternatif). Jakarta: Pusat Kajian Kinerja Kelembagaan Administrasi Negara.

ITDP \& GTZ. 2002. Angkutan Bus Cepat: Transportasi Berkelanjutan Panduan Bagi Pembuat Kebijakan di Kota-Kota Berkembang. Manfred Breithaupt, Germany.

Pujastaawa, Gde, Ida Bagus. 2016. Teknik Wawancara dan Observasi Untuk Mengumpulkan Bahan Informasi. Fakultas Sastra dan Budaya Universitas Udayana. Bali.

Jawa Post.com. Sabtu, 13 November 2021 https://www.jawapos.com/jpg-today/19/01/2017/jumlah bus-trans-metro-pekanbaru-hanya-mampu-layani-5koridor/

Dita, Kusuma, Monica. Wirawan, Adhitomo. 2020. Kinerja Bus Trans Batam Koridor I (Sekupang - Batam Center). Jurnal Manajemen Transportasi dan Logistik - Vol. 07 No. 03, November 2020 https://journal.itltrisakti.ac.id/index.php/jmtranslog

Dwiryanti, Aprisia. Ratnasari, Anita. 2013. Analisis Kinerja Pelayanan Bus Rapid Transit (BRT) Koridor II Terboyo-Sisemut (Studi Kasus: Rute Terboyo - Sisemut Kota Semarang). Jurnal Teknik PWK Volume 2 Nomor 32013 hal. 756-764 Online: http://ejournal-sl.undip.ac.id/index.php/pwk.

Fakhtian, Illyaza, Fatta. Budiharjo, Anton. 2021. Evaluasi Rute dan Lokasi Halte Bus Rapid Transit (BRT) Koridor II di Palangka Raya. Jurnal Manajemen Transportasi e Logistik - Vol. 08 No. 01, Maret2021

https://journal.itltrisakti.ac.id/index.php/jmtranslog

Gunawan, Kusnandar. 2011. Evaluasi Keberhasilan Transjakarta Dibandingkan Dengan Bus Rapid Transit (BRT) Kelas Dunia. Jurnal Jalan-Jembatan, Volume 28 No 2 Agustus 2011, 111125

Kurnianingtyas, Agnesia. Mardliyah, A`izzatul. Fauzizah, Kiki. 2020. Analisa Kinerja Bus Rapid Transit (BRT) Trans Semarang Koridor II Terminal Terboyo-Terminal Sisemut. Indonesian Journal of Spatial Planning. E-ISSN: 2723-0619 Vol. 1, No.2, 2020, 63 - 71. http://journals.usm.ac.id/index.php/ijsp

Nugroho, Adi. 2021. Identifikasi Potensi Bahaya di Ruang Tunggu Penumpang Bus Trans Kota Batam. Jurnal Manajemen Transportasi
\& Logistik - Vol. 08 No. 01, Maret

https://journal.itltrisakti.ac.id/index.php/jmtranslog

Nurfadli, Muhammad. Heriyanto, Dwi. Pratomo, Priyo. 2015. Evaluasi Kinerja Angkutan Massal Bus Rapid Transit Pada Koridor Rajabasa - Sukaraja. JRSDD, Edisi April 2015, Vol. 1, No. 1, Hal:205 - 220 (ISSN:2303-0011) https://journal.itltrisakti.ac.id/index.php/jmtranslog

Riawan, Anugra, Weldi. 2018. Analisis Pelayanan Bus Rapid Transit Kapasitas Sedang pada Sistem Transportasi Perkotaan Warta Penelitian Perhubungan 30 (2018) 119-132. 0852 1824/ 2580-1082 $\$ 2018$ Sekretariat Badan Penelitian dan Pengembangan Perhubungan Artikel ini open access dibawah lisensi CC BY-NC-SA

(https://creativecommons.org/licenses/by-nc-sa/4.0/) Nomor Akreditasi: (LIPI) 651/AU4/P2MI-LIPI/07/2015

Romadlon, Saintika. 2020. Preferensi Pengguna terhadap Layanan Bus Rapid Transit (BRT) Purwokerto-Purbalingga Jurnal Manajemen Transportasi \& Logistik - Vol. 07 No. 02, Juli 2020 https://journal.itltrisakti.ac.id/index.php/jmtranslog

Sitorus, Phillip,Jhon, Fredy. Nur Uddin, Wasni. 2020. Penentuan Lokasi Halte Transjabodetabek Ciputat-Blok M dengan Model Set Covering Problem. Jurnal Manajemen Transportasi \& Logistik-Vol. 07 No. 03, November 2020 https://journal.itltrisakti.ac.id/index.php/jmtranslog

Sulistyorini, Rahayu. 2021. Peran Infrastruktur Transportasi Dalam Pengembangan Provinsi Lampung. Jurnal Transportasi Vol. 21 No. 1 April 2021: 55-62

Valentine, Velie. Devi, Mutiasari. Pramana, Eka, Yunastiawan. 2020. Jangkauan Layanan Trans Yogya Terhadap Sebaran Aktivitas di Kawasan Perkotaan Yogyakarta. Jurnal Transportasi Vol. 20 No. 3 Desember 2020: 171-180.

Vidhia, Hendra. 2021. Evaluasi Kinerja Operasional Pelayanan Bus Rapid Transit (B Koridor Blok M-Kota, DKI Jakarta) Al-Kharaj: Jurnal Ekonomi, Keuangan \& Bisnis Syariah. Volume 3 No 1 (2021) 57-71 P-ISSN 2656-2871 E-ISSN 2656-435l DOI: 10.47467/alkharaj.v3il.188 